\title{
DISPONIBILIDADE DE NITROGÊNIO E SUA RELAÇÃO COM O AFILHAMENTO E O RENDIMENTO DE GRÃOS DE AVEIA
}

\author{
NITROGEN AVAILABILITY AND ITS RELATION WITH \\ OAT TILLERING AND GRAIN YIELD
}

\author{
Claudio Mario Mundstock ${ }^{1} \quad$ Christian Bredemeier $^{2}$
}

\section{RESUMO}

\begin{abstract}
O nitrogênio tem forte influência no crescimento $e$ desenvolvimento de aveia, nos estádios iniciais. Os afilhos, em especial, a sua produção e sobrevivência, têm relação com o rendimento de grãos e esses aspectos foram avaliados em relação à disponibilidade de $N$, em cinco experimentos conduzidos na Estação Experimental Agronômica/UFRGS (Eldorado do Sul, RS), no período de 1993 a 1998, com as cultivares UFRGS 10 e UFRGS 15. Os tratamentos consistiram na aplicação de $\mathrm{N}$ em: a) diferentes estádios de desenvolvimento (emergência ao emborrachamento) e b) diferentes doses na emergência das plantas. Em todas situações, esses tratamentos foram seguidos ou não pela aplicação de $N$ no final do afilhamento (emissão da $7^{\underline{a}}$ folha do colmo principal). $O$ afilhamento foi estimulado, especialmente, pelo $N$ aplicado no momento da emergência, devido à emissão de maior número de afilhos, e pelo $N$ aplicado na emissão da $7^{\underline{a}}$ folha, que foi importante para reduzir a mortalidade e manter a sincronia de desenvolvimento entre colmo principal e afilhos. Os melhores rendimentos de grãos foram obtidos quando a disponibilidade de $N$ foi elevada no período que engloba as épocas de emergência e final de afilhamento. A aplicação tardia de $N$ (emborrachamento) não resultou em aumento no rendimento de grãos. Na falta de suficiente suprimento de $N$ pelo solo, é necessária a aplicação combinada de nitrogênio na semeadura e por volta da emissão da $7^{\underline{a}}$ folha do colmo principal.
\end{abstract}

Palavras-chave: adubação nitrogenada, Avena sativa.

\section{SUMMARY}

Nitrogen shows a strong influence on oat growth and development, mainly on early stages of plant cycle. Oat tiller number and survival and grain yield as affected by nitrogen supply was studied in five field experiments at Estação Experimental Agronômica/UFRGS (Eldorado do Sul, RS), from 1993 through 1998, with cultivars UFRGS 10 and UFRGS 15. Treatments consisted in applying $N$ in different plant stages (emergence to booting) or in different levels at plant emergence. In all situations, treatments received or not an extra $N$-supply at the $7^{\text {th }}$ leaf stage. Tillering was stimulated mainly by $N$ applied at plant emergence for tiller emission and by $N$ applied at the $7^{\text {th }}$ leaf stage which reduced tiller mortality and mantained synchrony between main stem and tiller development. The best grain yields were obtained when $N$ was available from emergence up to $7^{\text {th }}$ leaf stage. Late $N$ application (booting stage) resulted in no yield increase. When soil nitrogen supply is restricted, $N$ should be applied at sowing and $7^{\text {th }}$ leaf emission.

Key words: top dressing, Avena sativa.

\section{INTRODUÇÃO}

O afilhamento é um processo de desenvolvimento em que gemas formadas nos nós basais do colmo de gramíneas se desenvolvem e produzem afilhos, produtivos ou não. A formação de afilhos normalmente se inicia quando a planta possui três folhas expandidas e, a partir desse estádio, para cada folha emitida no colmo principal, pode corresponder a emissão de um novo afilho (MASLE, 1985). Os afilhos são formados até a diferenciação da espigueta terminal, no ponto de crescimento (PETR et al., 1988), estando a planta com cerca de sete folhas completamente expandidas (LONGNECKER et al., 1993). Após, inicia-se a senescência dos afilhos não produtivos.

O afilhamento é fundamental na determinação do rendimento de grãos em aveia, pois afeta o número de panículas por área (DAVIDSON \& CHEVALIER, 1990). A sobrevivência de afilhos é determinada pela sua taxa de desenvolvimento em relação ao colmo principal. Assim, o período de tempo compreendido entre a emissão de duas folhas sucessivas (filocron)

\footnotetext{
${ }^{1}$ Engenheiro Agrônomo, PhD., Professor Titular, Departamento de Plantas de Lavoura, Faculdade de Agronomia, Universidade Federal do Rio Grande do Sul (UFRGS). Av. Bento Gonçalves, 7712, CP 776, 91540-970, Porto Alegre, RS. Bolsista do CNPq. E-mail: cmmundst@ufrgs.br. Autor para correspondência.

${ }^{2}$ Engenheiro Agrônomo, MSc., Professor Substituto, Departamento de Plantas de Lavoura, Faculdade de Agronomia, UFRGS. Recebido para publicação em 26.11.99. Aprovado em 05.07.00
} 
deve ser similar no colmo principal e nos afilhos (sincronismo de desenvolvimento) para que essas estruturas possam sobreviver e produzir grãos (MASLE, 1985).

A recomendação para a aplicação de $\mathrm{N}$ em cobertura tem relação com o processo de afilhamento, afetando a emissão e a sobrevivência de afilhos. A alta disponibilidade de N, no início do desenvolvimento, pode estimular a maior emissão dessas estruturas (LONGNECKER et al., 1993), enquanto que a aplicação de $\mathrm{N}$, antes da expansão dos entrenós, incrementa a sobrevivência dos afilhos já emitidos (SHAH $\boldsymbol{e t} \boldsymbol{a l} .$, 1994). O efeito da maior disponibilidade de $\mathrm{N}$ sobre a sobrevivência dos afilhos se dá pela manutenção do sincronismo de desenvolvimento entre o colmo principal e os afilhos (MASLE, 1985). Condições desfavoráveis de ambiente retardam o aparecimento ou provocam a omissão de afilhos (KLEPPER et al., 1982). Fatores de manejo, como densidade de semeadura, controle de moléstias e cultivar utilizada (SIMONS, 1982) também provocam alterações no processo de afilhamento e são determinantes para estabelecer o momento mais adequado de aplicação de $\mathrm{N}$.

A atual recomendação para os Estados do Rio Grande do Sul e Santa Catarina (COMISSÃO..., 1997) é a aplicação de N em cobertura no início do afilhamento, sem caracterizar a extensão do período crítico, nem os reflexos que a variação na época de aplicação tem sobre o afilhamento. Visando a estudar essas características, o presente trabalho foi delineado com a suplementação de $\mathrm{N}$ na emergência, início e final do afilhamento, para avaliar as conseqüências sobre o número de afilhos produzidos, a sobrevivência desses e o rendimento de grãos.

\section{MATERIAL E MÉTODOS}

Cinco experimentos com a cultura da aveia foram realizados a campo, na Estação Experimental Agronômica da Universidade Federal do Rio Grande do Sul (EEA/UFRGS, Eldorado do Sul, RS), nos anos de 1993, 1994, 1995, 1997 e 1998. A EEA/UFRGS está localizada na região fisiográfica da Depressão Central. O solo da área experimental é classificado como ARGISSOLO VERMELHO Distrófico típico.

A análise química do solo antes da instalação dos experimentos foi determinada, a cada ano, em amostras retiradas na profundidade de $0-20 \mathrm{~cm}$. $\mathrm{O}$ teor de matéria orgânica foi de $24,20,23$ e $28 \mathrm{~g} . \mathrm{kg}^{-1}$; o pH em água foi de 5,9; 6,2; 5,7; e 5,5; o teor de $\mathrm{P}$ disponível foi de 6,$9 ; 8 ; 15$ e $14 \mathrm{mg} . \mathrm{kg}^{-1} \mathrm{e}$ de potássio disponível foi de $124 ; 119 ; 175 ; 162$ e 256mg.kg ${ }^{-1}$, para os anos de 1993, 1994, 1995, 1997 e 1998, respectivamente.

Os tratamentos, no ano de 1993, consistiram da aplicação ou não de $40 \mathrm{~kg}$ N/ha na emergência das plantas, seguidas ou não da aplicação de $40 \mathrm{~kg}$ N/ha na emissão da $7^{\text {a }}$ folha do colmo principal. Em 1994 e 1995, os tratamentos consistiram da aplicação de $40 \mathrm{~kg}$ N/ha nos seguintes estádios de desenvolvimento das plantas: emergência; emissão da $3^{\mathrm{a}}$ folha; emissão da $5^{\mathrm{a}}$ folha; emissão da $7^{\text {a }}$ folha; e emborrachamento (panícula envolta na bainha da folha bandeira, durante o período de alongamento dos entrenós). As aplicações nos três primeiros estádios foram seguidas ou não pela aplicação de $40 \mathrm{~kg}$ N/ha por ocasião da emissão da $7^{\text {a }}$ folha. Em 1997, os tratamentos consistiram da aplicação de $20 \mathrm{~kg} / \mathrm{ha}$ e $40 \mathrm{~kg} / \mathrm{ha}$ de $\mathrm{N}$ na emergência, seguidos da aplicação ou não de $40 \mathrm{~kg}$ N/ha na emissão da $7^{\text {a }}$ folha. Em 1998, os tratamentos consistiram em diferentes disponibilidades de $\mathrm{N}$ na emergência (sem $\mathrm{N}, 20$, 40, 60 e 80kg/ha), seguidos ou não da aplicação de $40 \mathrm{~kg} \mathrm{~N} / \mathrm{ha}$ na emissão da $7^{\mathrm{a}}$ folha. A cultivar de aveia utilizada em 1993 e 1994 foi a UFRGS 10 e em 1995, 1997 e 1998, a cultivar UFRGS 15.

A adubação de base (na semeadura) das áreas experimentais consistiu da aplicação de 75 e $45 \mathrm{~kg} / \mathrm{ha}$ de $\mathrm{P}_{2} \mathrm{O}_{5}$ e $\mathrm{K}_{2} \mathrm{O}$, respectivamente, nos cinco anos de experimentação. A semeadura direta foi realizada, em cada ano, no final de junho, na densidade de 300 sementes aptas $/ \mathrm{m}^{2}$. A área de cada experimento estava no sistema plantio direto há mais de 4 anos, cultivando-se soja e milho, alternadamente, no verão, e aveia preta no inverno, a qual era dessecada no florescimento. Em 1993, 1994, 1995 e 1997, o milho foi a cultura anterior à aveia branca, tendo produzido cerca de $5 \mathrm{Mg} / \mathrm{ha}$ de palha. Em 1998, a cultura anterior foi a soja (cerca de $5 \mathrm{Mg} / \mathrm{ha}$ de massa verde, roçada no florescimento). $\mathrm{O}$ delineamento experimental foi $\mathrm{o}$ de blocos ao acaso (quatro repetições) e cada parcela foi constituída de 10 linhas com $5 \mathrm{~m}$ de comprimento, com $0,17 \mathrm{~m}$ entre linhas. Os tratos fitossanitários consistiram no tratamento das sementes com o fungicida Triadimenol $(1 \mathrm{~g}$ i.a. $/ \mathrm{kg}$ semente) e a aplicação do fungicida Tebuconazole (0,75 L/ha de Folicur), quando do aparecimento das primeiras pústulas de ferrugem da folha. Durante a realização dos experimentos, as condições de umidade do solo foram adequadas para a solubilização do adubo nitrogenado (uréia).

No experimento de 1993, foi avaliado o número de afilhos emitidos, em duas ocasiões [emissão da $7^{\mathrm{a}}$ folha e emissão da $9^{\mathrm{a}}$ folha, correspondendo a 53 e 72 dias após emergência (DAE), respectivamente]. Em 1994, foram 
avaliados o estádio de desenvolvimento do colmo principal e do $1^{\circ}$ afilho (formado na axila da $1^{\mathrm{a}}$ folha do colmo principal) e a dinâmica do afilhamento, em plantas amostradas em $1,5 \mathrm{~m}$ de linha $\left(0,225 \mathrm{~m}^{2}\right)$, em cada repetição. O estádio de desenvolvimento foi determinado utilizando-se a escala proposta por HAUN (1973). $O$ valor dado pela escala reflete $\mathrm{O}$ número de folhas completamente expandidas da planta, mais as unidades decimais da última folha (em expansão) relativas à anterior. Por exemplo, uma planta na escala Haun 3.7 tem a terceira folha completamente expandida e a quarta folha possuindo sete décimos do comprimento da terceira. A dinâmica do afilhamento foi avaliada através da contagem do número de afilhos emitidos nas plantas amostradas. As amostragens foram realizadas, semanalmente, entre os dias 07 de julho de 1994 (escala Haun 1.0) e 08 de setembro de 1994 (escala Haun 9.0), perfazendo um total de dez determinações. A aplicação de $\mathrm{N}$ por ocasião da emissão da $7^{\mathrm{a}}$ folha (escala Haun 6.1) coincidiu com a sétima avaliação (17 de agosto de 1994). Nos anos de 1995, 1997 e 1998, foi avaliado o rendimento de grãos. O rendimento de grãos foi avaliado em todos os anos. Os diferentes parâmetros foram submetidos à análise de variância (F-teste) e a comparação entre médias, quando houve significância para as diferenças entre tratamentos, foi feita através do teste de Duncan, em nível de significância de $5 \%$.

\section{RESULTADOS E DISCUSSÃO}

Os afilhos primários foram avaliados no experimento de 1994 até a emissão da $9^{\text {a }}$ folha do colmo principal. $\mathrm{O}$ número máximo de afilhos $/ \mathrm{m}^{2}$ sob três disponibilidades de $\mathrm{N}$ na base, como mostrado na figura 1, ocorreu, aproximadamente, entre os estádios correspondentes à escala Haun 5.0 e 7.0 (40 a 55 DAE) (Figuras 1.a, 1.b e 1.c). Esse número variou com a época de aplicação de $\mathrm{N}$ na base (Figura 1). Com a suplementação de $\mathrm{N}$ na emergência, as plantas emitiram um grande número de afilhos (acima de 300 afilhos $/ \mathrm{m}^{2}$ ) (Figura 1.a), bem como
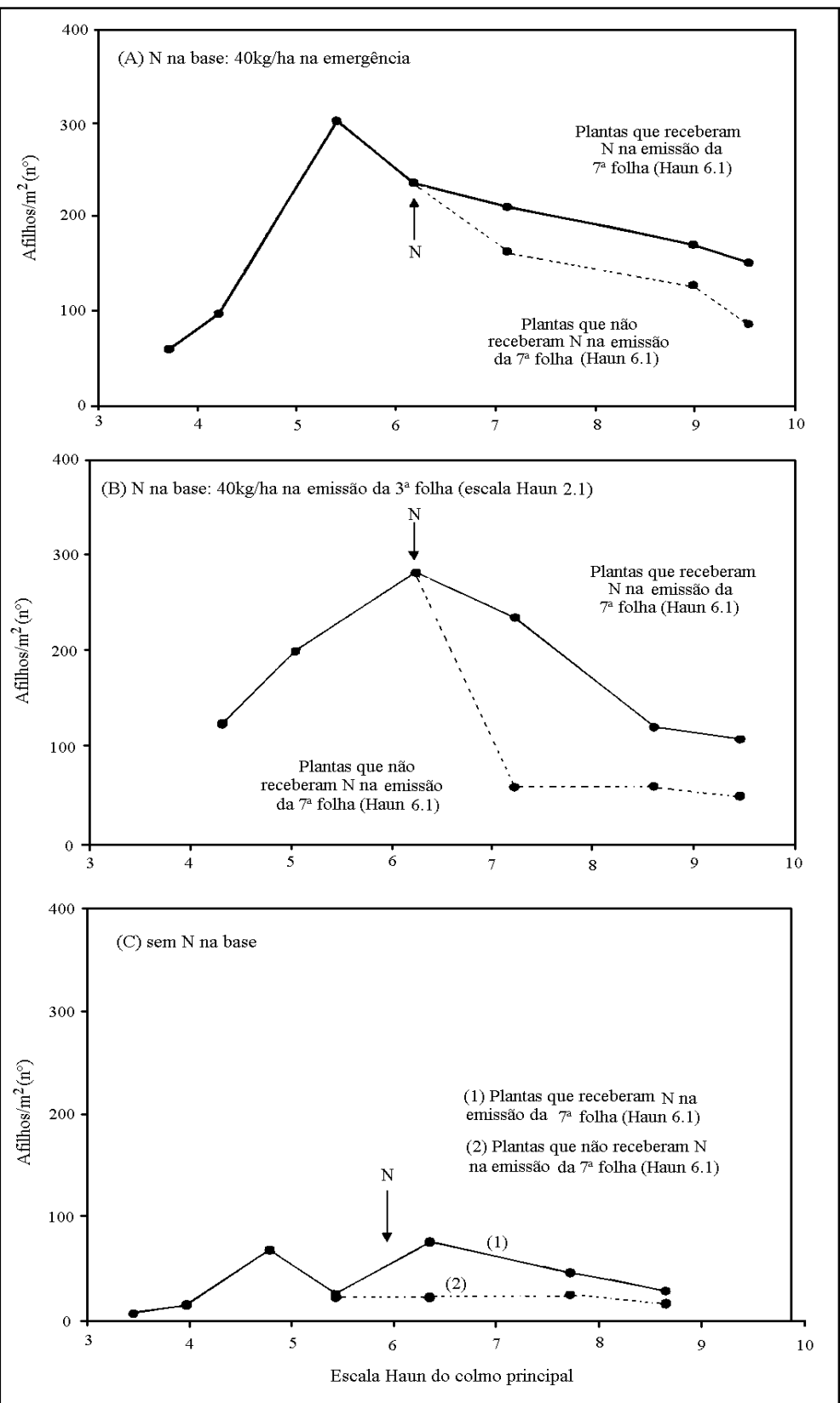

Figura 1 - Evolução do número de afilhos por $\mathrm{m}^{2}$ na cv. UFRGS 10, em tratamentos com e sem aplicação de $\mathrm{N}$ no momento de emissão da $7^{\underline{a}}$ folha do colmo principal. 1994. Setas indicam o momento de aplicação de $\mathrm{N}$ em cobertura.

no tratamento com $\mathrm{N}$ na emissão da $3^{\mathrm{a}}$ folha (cerca de 280 afilhos $/ \mathrm{m}^{2}$ ) (Figura 1.b). A aplicação de $\mathrm{N}$ no início do desenvolvimento é importante para aumentar o número dessas estruturas, pois a definição da emissão ou não de afilhos em aveia ocorre muito precocemente no ciclo da planta (entre os estádios de uma e duas folhas expandidas), conforme mostrado por ALMEIDA (1998) e ALVES (1998), e essa pode ser afetada pela disponibilidade de N. O estímulo inicial que o $\mathrm{N}$ 
promove sobre a produção de afilhos é fundamental para a determinação do número de panículas por área, uma vez que os primeiros afilhos emitidos possuem maiores chances de sobreviver e contribuir para o aumento do rendimento de grãos.

Além disso, a disponibilidade de $\mathrm{N}$ no início do ciclo é importante para que não ocorra a omissão de afilhos primários, fato observado por LONGNECKER et $\boldsymbol{a l}$. (1993) em trigo. Por essa razão, a falta de $\mathrm{N}$ durante o ciclo reduziu o número de afilhos emitidos (Figura 1.c), o que se refletiu no baixo rendimento de grãos (Tabela 1).

A sobrevivência dos afilhos emitidos é afetada pela disponibilidade de $\mathrm{N}$, que deve ser elevada após o momento de máxima produção de afilhos, para manter o sincronismo de emissão de folhas entre o colmo principal e os afilhos e, com isso, contribuir para a sua sobrevivência. Isso foi medido pela escala Haun (número de folhas emitidas) nos primeiros 70 DAE, tanto no colmo principal quanto no $1^{\mathrm{o}}$ afilho (Figura 2 ). Os maiores valores da escala Haun foram observados nos tratamentos que receberam $\mathrm{N}$ no período da emergência (Figura 2.a) até a emissão da $3^{\mathrm{a}}$ folha (escala Haun 2.1) (Figura 2.b), tanto para o número de folhas emitidas no colmo principal como no $1^{\mathrm{o}}$ afilho. A deficiência de $\mathrm{N}$, no início do ciclo reduziu este número, o que pode ser verificado pelos menores valores da escala Haun aos 70 DAE

Tabela 1 - Rendimento de grãos das cultivares de aveia UFRGS 10 (1993 e 1994) e UFRGS 15 (1995), em função do estádio de aplicação de nitrogênio.

\begin{tabular}{|c|c|c|c|}
\hline \multirow{3}{*}{$\begin{array}{l}\text { Estádio de } \\
\text { aplicação de N } \\
\text { sem N }\end{array}$} & \multicolumn{3}{|c|}{ Rendimento de grãos (kg/ha) } \\
\hline & \multirow{2}{*}{$\frac{1993}{1100 c^{1 /}}$} & \multirow{2}{*}{$\frac{1994}{1767 \mathrm{gh}}$} & \multirow{2}{*}{$\begin{array}{c}1995 \\
1871 \mathrm{bc}\end{array}$} \\
\hline & & & \\
\hline Emergência $^{2 /}$ & $2177 \mathrm{~b}$ & $3130 \mathrm{abc}$ & $2230 \mathrm{ab}$ \\
\hline Emissão da $3^{\text {a }}$ folha $^{3 /}$ & $-5 /$ & 2468 ef & $2168 \mathrm{abc}$ \\
\hline Emissão da $5^{\text {a }}$ folha & - & 2652 cde & $2313 \mathrm{ab}$ \\
\hline Emissão da $7^{\text {a }}$ folha & $1766 \mathrm{bc}$ & 2736 bcd & $2088 \mathrm{abc}$ \\
\hline Emborrachamento & - & $1703 \mathrm{~h}$ & $1816 \mathrm{c}$ \\
\hline Emergência $+7^{-\mathrm{a}}$ folha $^{4 /}$ & $3183 a$ & $3590 \mathrm{a}$ & $2580 \mathrm{a}$ \\
\hline $3^{a}$ folha $+7^{a}$ folha & - & $3270 \mathrm{ab}$ & $2359 \mathrm{ab}$ \\
\hline $5^{\mathrm{a}}$ folha $+7^{\mathrm{a}}$ folha & - & 2969abcd & $2390 \mathrm{ab}$ \\
\hline \multicolumn{4}{|c|}{$\begin{array}{l}\text { Médias seguidas pela mesma letra na coluna não diferem } \\
\text { significativamente entre si pelo Teste de Duncan, em nível de } 5 \% \text {. } \\
\text { 2/ Aplicação de } 40 \mathrm{~kg} \mathrm{~N} / \text { ha na emergência das plantas. } \\
\text { 3/ Aplicação de } 40 \mathrm{~kg} \mathrm{~N} / \mathrm{ha} \text { na emissão da } 3^{-a} \text { folha (escala } \\
\text { Haun } 2.1 \text { ). } \\
\text { 4/ Aplicação de } 40 \mathrm{~kg} \mathrm{~N} / \mathrm{ha} \text { na emergência }+40 \mathrm{~kg} \mathrm{~N} / \mathrm{ha} \text { na emissão } \\
\text { (escala Haun } 6.1 \text { ). } \\
\text { 5/ Tratamento não delineado. }\end{array}$} \\
\hline
\end{tabular}

(Figura 2.c). A sobrevivência e o sincronismo de desenvolvimento podem ser melhorados quando o $\mathrm{N}$ é aplicado no final do afilhamento, como nos tratamentos que receberam esse nutriente por ocasião da emissão da $7^{\text {a }}$ folha do colmo principal (escala Haun 6.1).

Com relação à sobrevivência, nas situações mostradas na figura 1 , o $\mathrm{N}$ em cobertura alterou a dinâmica do afilhamento. Sobre os afilhos já presentes, retardou a senescência e aumentou a sua sobrevivência (Figuras 1.a, 1.b e 1.c), o que, possivelmente, tenha se refletido no aumento do número de panículas por área, semelhante ao observado por SHAH et al. (1994) em trigo. No tratamento sem $\mathrm{N}$ na base, a aplicação de $\mathrm{N}$ na emissão da $7^{\mathrm{a}}$ folha estimulou a emissão tardia de afilhos (Figura 1.c). Contudo, os afilhos emitidos tardiamente têm baixa capacidade de competição, sendo a sua taxa de sobrevivência muito baixa (FRASER et al., 1982). Além disso, reduzem a penetração de luz na comunidade, causando forte competição entre colmos (PETR et al., 1988). Por outro lado, sem $\mathrm{N}$ em cobertura, observou-se alta mortalidade de afilhos (Figuras 1.a, 1.b e 1.c), o que se refletiu em menores rendimentos de grãos, em comparação àqueles tratamentos em que foi aplicado o nitrogênio (Tabela 1).

Quanto ao sincronismo de desenvolvimento, a aplicação de $\mathrm{N}$ na emissão da $7^{\mathrm{a}}$ folha (escala Haun 6.1) manteve a taxa de emissão de folhas no $1^{\circ}$ afilho mais próxima àquela do colmo principal, em comparação às plantas que não receberam $\mathrm{N}$ nesse estádio (Figuras 2.a, 2.b e 2.c). $\mathrm{Na}$ ausência de $\mathrm{N}$ a partir da emissão da $7^{\mathrm{a}}$ folha, o $1^{\text {o }}$ afilho praticamente não emitiu mais folhas, levando à perda de sincronia de desenvolvimento entre colmo principal e afilho e determinando o início da senescência dessas estruturas, como observado por MASLE (1985). Nota-se que a taxa de emissão de folhas no colmo principal não foi afetada pela aplicação ou não de $\mathrm{N}$ na emissão da $7^{\text {a }}$ folha (Figuras 2.a, 2.b e 2.c), indicando que a falta de $\mathrm{N}$ é mais prejudicial à emergência de folhas no $1^{\text {o }}$ afilho do que no colmo principal, levando à morte de afilhos. Essa resposta foi similar à obtida em trigo por LONGNECKER et al. (1993).

Os reflexos da adubação nitrogenada foram constatados no rendimento de grãos, nas duas cultivares. Nos casos em que o $\mathrm{N}$ foi adicionado em apenas uma ocasião, os melhores resultados foram obtidos quando ele foi aplicado o mais cedo possível (semeadura/emergência) (Tabela 1), em decorrência do efeito dessa aplicação inicial sobre o aumento no número de afilhos emitidos (Figura 

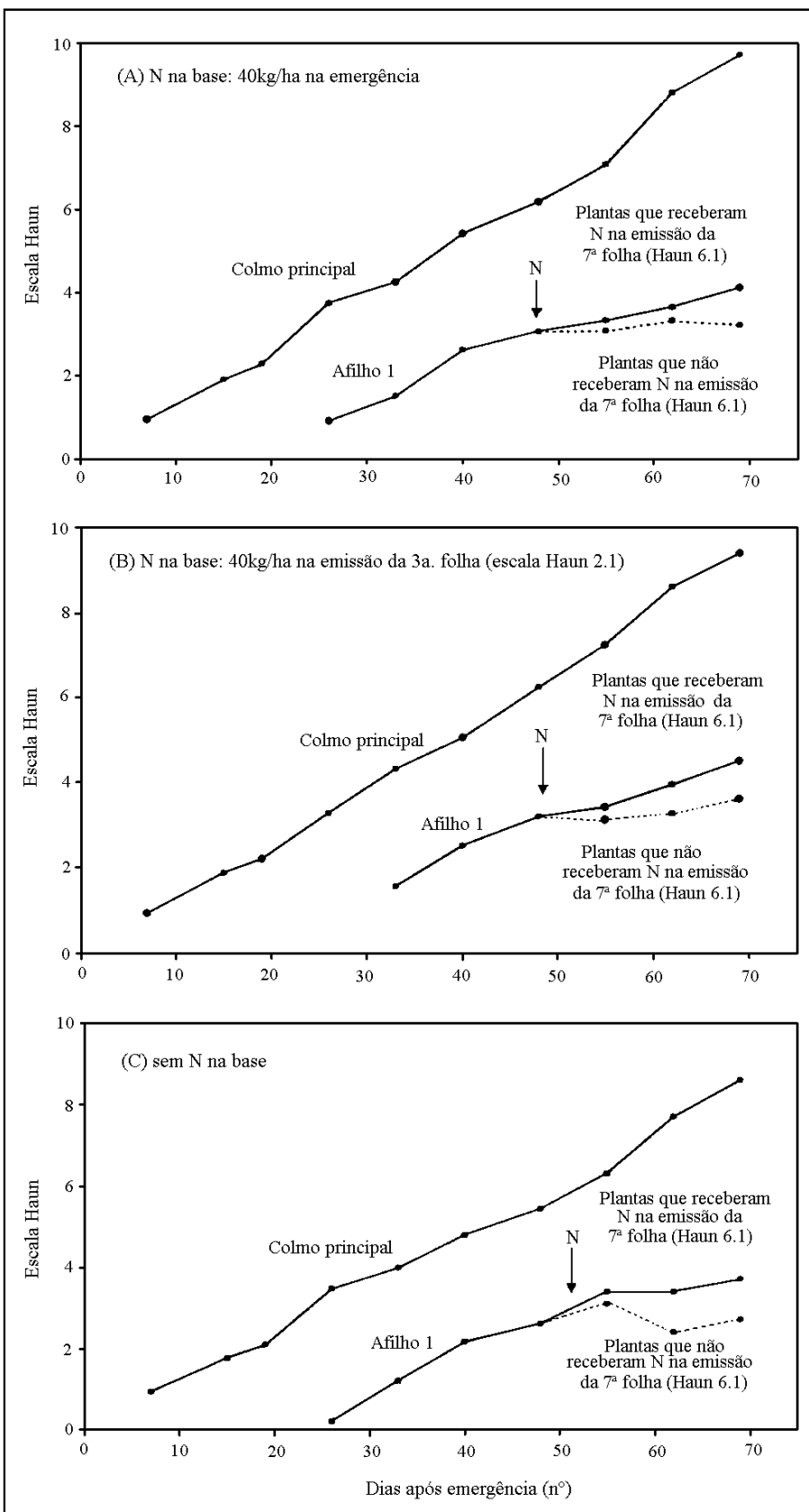

Figura 2 - Desenvolvimento foliar (escala Haun) do colmo principal e primeiro afilho na cv. UFRGS 10, em tratamentos com e sem aplicação de $\mathrm{N}$ no momento de emissão da $7^{\mathrm{a}}$ folha do colmo principal. 1994. Setas indicam o momento de aplicação de $\mathrm{N}$ em cobertura.

1.a). Com a aplicação de $\mathrm{N}$ na emissão da $3^{\text {a }}$ folha, os rendimentos decresceram em relação à época anterior (Tabela 1). No entanto, os rendimentos voltaram a crescer quando a aplicação de $\mathrm{N}$ ocorreu na emissão da $5^{\text {a }}$ folha (1995) ou $7^{\text {a }}$ folha (1994), pelo efeito da aplicação tardia sobre a maior sobrevivência de afilhos (Figuras 1.a, 1.b e 1.c).
Isso indica que, em aveia, há dois momentos críticos para melhor resposta ao N: no início do ciclo e por volta da emissão da $5^{5^{\mathrm{a}}}-7^{\mathrm{a}}$ folha do colmo principal.

Nos anos de 1994 e 1995, optou-se por variar a $1^{\underline{a}}$ época de aplicação de $\mathrm{N}$ (da emergência à emissão da $5^{\text {a }}$ folha) e manter fixa a época da $2^{\text {a }}$ aplicação do $\mathrm{N}$ (emissão da $7^{\mathrm{a}}$ folha). Nessas combinações, a melhor resposta foi obtida quando o $\mathrm{N}$ foi aplicado na emergência, seguida da aplicação de $\mathrm{N}$ na emissão da $7^{\mathrm{a}}$ folha (Tabela 1 ). $\mathrm{O}$ efeito da aplicação combinada de $\mathrm{N}$ nesses dois estádios decorreu dos efeitos específicos sobre a produção e a sobrevivência de afilhos (Figura 1), conforme relatado anteriormente.

A combinação dessas duas épocas de aplicação de $\mathrm{N}$ pode ser mostrada pelos dados de afilhamento obtidos no experimento de 1993 (Tabela 2). A disponibilidade de $\mathrm{N}$ no início do ciclo afetou o número de afilhos emitidos, visualizado pelo número de afilhos $/ \mathrm{m}^{2}$ na emissão da $7^{\text {a }}$ folha do colmo principal (Tabela 2). Já a disponibilidade de $\mathrm{N}$ na emissão da $7^{\text {a }}$ folha afetou a sobrevivência de afilhos e a emissão tardia de afilhos analisados quando da emissão da $9^{-a}$ folha (Tabela 2).

Determinados os dois momentos críticos, procurou-se avaliar em qual deles foi mais essencial o suprimento de N. Os resultados obtidos da aplicação única na emergência, comparada com a aplicação única de $\mathrm{N}$ na emissão da $7^{\mathrm{a}}$ folha (Tabela 1), mostraram que, para a cv. UFRGS 10, nas condições climáticas de 1994, o N inicial foi mais importante. Já na cv. UFRGS 15, no ano de 1995, as duas épocas foram igualmente críticas (Tabela 1).

Os estudos de 1997 e 1998 foram feitos para testar as respostas à aplicação de $\mathrm{N}$ nas duas épocas críticas, variando a disponibilidade desse nutriente no início do ciclo. Os resultados indicaram que, independente da dose de $\mathrm{N}$ aplicada na base, sempre que essa aplicação foi seguida da suplementação adicional de N (40kg/ha) no final do afilhamento (emissão da $7^{\text {a }}$ folha), observou-se um incremento no rendimento de grãos (Figura 3), decorrente do aumento no número de afilhos sobreviventes e produtivos. Essa resposta foi 
Tabela 2 - Número de afilhos por $\mathrm{m}^{2}$, na cultivar UFRGS 10, aos 53 dias (emissão da $7^{\text {a }}$ folha) e 72 dias (emissão da $9^{a}$ folha) após emergência, em função da aplicação de nitrogênio na emergência e na emissão da $7^{\text {a }}$ folha do colmo principal.

\begin{tabular}{lccc}
\hline $\begin{array}{l}\text { N na emergência } \\
(40 \mathrm{~kg} / \mathrm{ha})\end{array}$ & $\begin{array}{c}\text { Afilhos } / \mathrm{m}^{2} \text { na } \\
\text { emissão da } 7^{\mathrm{a}} \text { folha } \\
\left(\mathrm{n}^{\circ}\right)\end{array}$ & $\begin{array}{c}\text { N em cobertura na } \\
\text { emissão da } 7^{\mathrm{a}} \text { folha } \\
(40 \mathrm{~kg} / \mathrm{ha})\end{array}$ & $\begin{array}{c}\text { Afilhos } / \mathrm{m}^{2} \text { na } \\
\text { emissão da } 9^{\mathrm{a}} \text { folha } \\
\left(\mathrm{n}^{\circ}\right)\end{array}$ \\
\hline Com N & $240 \mathrm{a}^{1 /}$ & Com N & $196 \mathrm{a}$ \\
& & Sem N & $58 \mathrm{bc}$ \\
Sem N & $60 \mathrm{~b}$ & Com N & $90 \mathrm{~b}$ \\
& & Sem N & $0 \mathrm{c}$
\end{tabular}

${ }^{1 /}$ Médias seguidas pela mesma letra na coluna não diferem significativamente entre si pelo Teste de Duncan, em nível de $5 \%$ de significância.

verificada inclusive no ambiente com alta disponibilidade de N (1998 - pós soja), o que propiciou elevados rendimentos de grãos (em torno de 4000-4500kg/ha). É importante observar que, a partir da dose de $40 \mathrm{~kg} / \mathrm{ha}$ de $\mathrm{N}$ na base, as respostas à suplementação de $\mathrm{N}$ em cobertura começaram a diminuir, pois ocorreu acamamento de plantas nos tratamentos que receberam mais de $40 \mathrm{~kg}$ da $7^{\mathrm{a}}$ folha.

A aplicação de N no emborrachamento não resultou em aumento de rendimento de grãos e foi similar ao tratamento que não recebeu $\mathrm{N}$, em ambas cultivares (Tabela 1). Em alguns casos, a aplicação tardia de $\mathrm{N}$ pode aumentar a massa do grão, em função da manutenção da área foliar ativa por um período mais longo (McMASTER, 1997) e resultar em pequenos incrementos de rendimento.

Os resultados demonstraram que as plantas de aveia exigem grande disponibilidade de $\mathrm{N}$ no início do ciclo, com visíveis efeitos sobre o rendimento de grãos. Indicaram também que a aplicação de $\mathrm{N}$, em cobertura, no final do afilhamento é importante, especialmente em solos com baixo teor de matéria orgânica, como o que foi utilizado, que tem baixa capacidade de suprir $\mathrm{N}$ às plantas. Nessa situação, a suplementação com $\mathrm{N}$ em cobertura pode

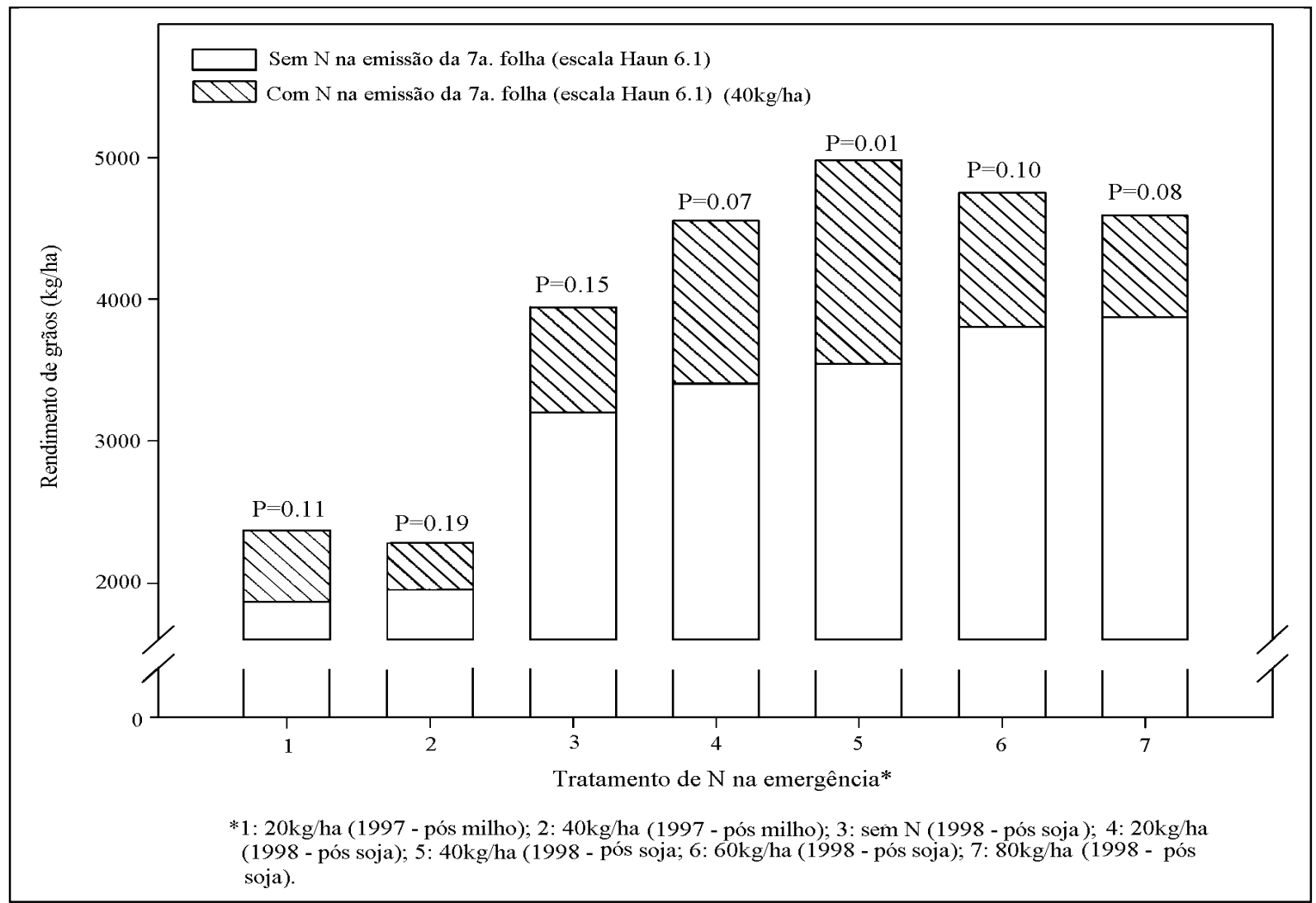

Figura 3 - Acréscimo no rendimento de grãos na cv. UFRGS 15, em função da aplicação de $\mathrm{N}$ no momento de emissão da $7^{\mathrm{a}}$ folha do colmo principal, em diferentes tratamentos de N na base. 1997 e 1998. Médias dentro do mesmo tratamento de N na base diferem entre si em nível de significância indicado (F-teste). 
disponibilizar esse nutriente no momento de grande consumo pela planta, alterando a dinâmica do afilhamento e otimizando o rendimento de grãos.

\section{CONCLUSÕES}

- O número de afilhos em aveia é estimulado com a aplicação de nitrogênio o mais cedo possível, de preferência na emergência das plantas e no período que vai da emergência à emissão da $7^{\text {a }}$ folha do colmo principal;

- o nitrogênio aplicado às plantas de aveia, próximo à emissão da $7^{\text {a }}$ folha, é importante para manter a sincronia de desenvolvimento foliar entre colmo principal e primeiro afilho, reduzindo a sua mortalidade;

- os melhores rendimentos de grãos de aveia são obtidos com a aplicação combinada de $\mathrm{N}$ na emergência e na emissão da $7^{\mathrm{a}}$ folha;

- a aplicação de $\mathrm{N}$ no final do afilhamento da aveia, na maioria dos casos, foi efetiva em aumentar o rendimento de grãos mesmo quando a disponibilidade de $\mathrm{N}$ no início do ciclo foi elevada;

- a aplicação tardia de N, no emborrachamento, não ocasiona acréscimos no rendimento de grãos.

\section{REFERÊNCIAS BIBLIOGRÁFICAS}

ALMEIDA, M.L. Modificação do afilhamento de trigo e aveia pela qualidade da luz. Porto Alegre - RS, 1998. 121p. Tese (Doutorado em Fitotecnia) - Programa de Pósgraduação em Fitotecnia, Universidade Federal do Rio Grande do Sul, 1998.

ALVES, A.C. Mecanismos de controle do desenvolvimento de afilhos em cereais de estação fria. Porto Alegre - RS, 1998. 115p. Tese (Doutorado em Fitotecnia) - Programa de Pós-graduação em Fitotecnia, Universidade Federal do Rio Grande do Sul, 1998.
COMISSÃO DE FERTILIDADE DO SOLO - RS/SC. Recomendações de adubação e de calagem para os estados do Rio Grande do Sul e Santa Catarina. 3. ed. Passo Fundo: SBCS- Núcleo Regional Sul, 1997. 224p.

DAVIDSON, D.J., CHEVALIER, P.M. Preanthesis tiller mortality in spring wheat. Crop Science, Madison, v.30, n.4, p.832-836, 1990 .

FRASER, J., DOUGHERTY, C.T., LANGER, R.H.M. Dynamics of tiller populations of standart height and semidwarf wheats. New Zealand Journal of Agricultural Research, Wellington, v.25, p.321-328, 1982.

HAUN, J.R. Visual quantification of wheat development. Agronomy Journal, Madison, v.65, n.1, p.116-119, 1973.

KLEPPER, B., RICKMAN, R.W., PETERSON, C.M. Quantitative characterization of vegetative development in small cereals grains. Agronomy Journal, Madison, v.74, n.5, p.789-792, 1982 .

LONGNECKER, N., KIRBY, E.J.M., ROBSON, A. Leaf emergence, tiller growth, and apical development of nitrogen-deficient spring wheat. Crop Science, Madison, v.33, n.1, p.154-160, 1993.

MASLE, J. Competition among tillers in winter wheat: consequences for growth and development of the crop. In: DAY, W., ATKIN, R.K. (eds.). Wheat growth and modelling. New York : Plenum, 1985. p.33-54.

McMASTER, G.S. Phenology, development and growth of the wheat (Triticum aestivum L.) shoot apex: a review. Advances in Agronomy, San Diego, v.59, p.63-118, 1997.

PETR, J., CRENY, V., HRUSKA, L. Yield formation in cereals. In: PETR, J., CRENY, V., HRUSKA, L. Yield formation in the main field crops. Amsterdam : Elsevier, 1988. p.72153.

SHAH, S.A., HARRISON, S.A., BOQUET, D.J., et al. Management effects on yield and yield components of lateplanted wheat. Crop Science, Madison, v.34, n.5, p.12981303, 1994.

SIMONS, R.G. Tiller and ear production of winter wheat. Field Crop Abstracts, Wallingford, v.35, p.857-870, 1982.

Ciência Rural, v. 31, n. 2, 2001 